\title{
Evaluation of wave loads on a new type of perforated caisson
}

1 Miguel Vázquez MSc Civil Engineer

Dragados, S.A. Technical Directorate, Marine Works, Madrid, Spain (corresponding author: mvazquezr@dragados.com)

2 Vicente Negro PhD

Associate Professor, Universidad Politécnica de Madrid, Madrid, Spain
3 José Santos López-Gutiérrez PhD

Assistant Professor, Universidad Politécnica de Madrid, Madrid, Spain

4 José Luis Monsó PhD

Associate Professor, Universidad Politécnica de Cataluña (UPC), Barcelona, Spain; Senior Advisor, SENER, Basque Country, Spain
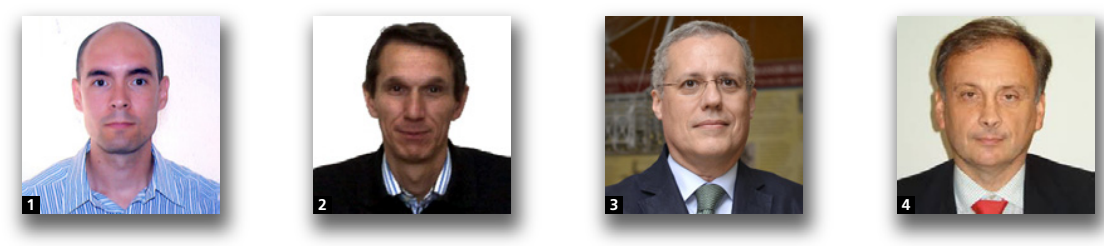

A new type of perforated breakwater has been tested combining the advantages of cylindrical geometry with stepped wave energy dissipation. Thus, the new type of caisson implies a significant reduction of maximum wave forces, as well as loads transmitted to the foundation in comparison with conventional vertical breakwater and other types of perforated caissons. Starting from a brief description of the model and test results, this paper describes the development of a methodology for the estimation of maximum wave loads on this type of breakwater, in order to become a generalisable tool for predesign purposes. Construction and installation constraints of this new type of caisson are also assessed. These need to be taken into account in order to keep some advantages from the proposed design, while noting the key factors from a practical point of view.

\section{Notation}

$A \quad$ orbital amplitude of the wave movement

$B \quad$ chamber width

$B_{\text {eq }} \quad$ width of rubble berm, averaged over height of berm $\left(h_{\mathrm{b}}\right)$

$B^{*} \quad$ relative berm width (McConnell)

$B / L \quad$ relative chamber width

$C_{\mathrm{d}} \quad$ drag coefficient

$C_{\mathrm{e}} \quad$ effective drag coefficient

$C_{\mathrm{M}} \quad$ inertia coefficient, $C_{\mathrm{M}}=1+C_{\mathrm{m}}$

$C_{\mathrm{m}} \quad$ added mass coefficient

$D, D_{\text {front }} \quad$ cylinder's diameter in the front wall

$d \quad$ water depth over berm in front of the caisson

$d^{\prime} \quad$ water depth inside the caisson chamber

$E^{\prime} \quad$ incident wave energy per unit length

$F_{\text {calc }} \quad$ estimated horizontal wave force according to the predictive model for this new type of caisson

$F_{\text {conv }}$

$F_{\mathrm{d}}$

$F_{\text {h+ve max }}$

$F_{\text {h-ve } \max }$ peak horizontal wave loads in a conventional vertical wall drag force maximum horizontal wave forces on the structure maximum seaward wave forces on the structure 


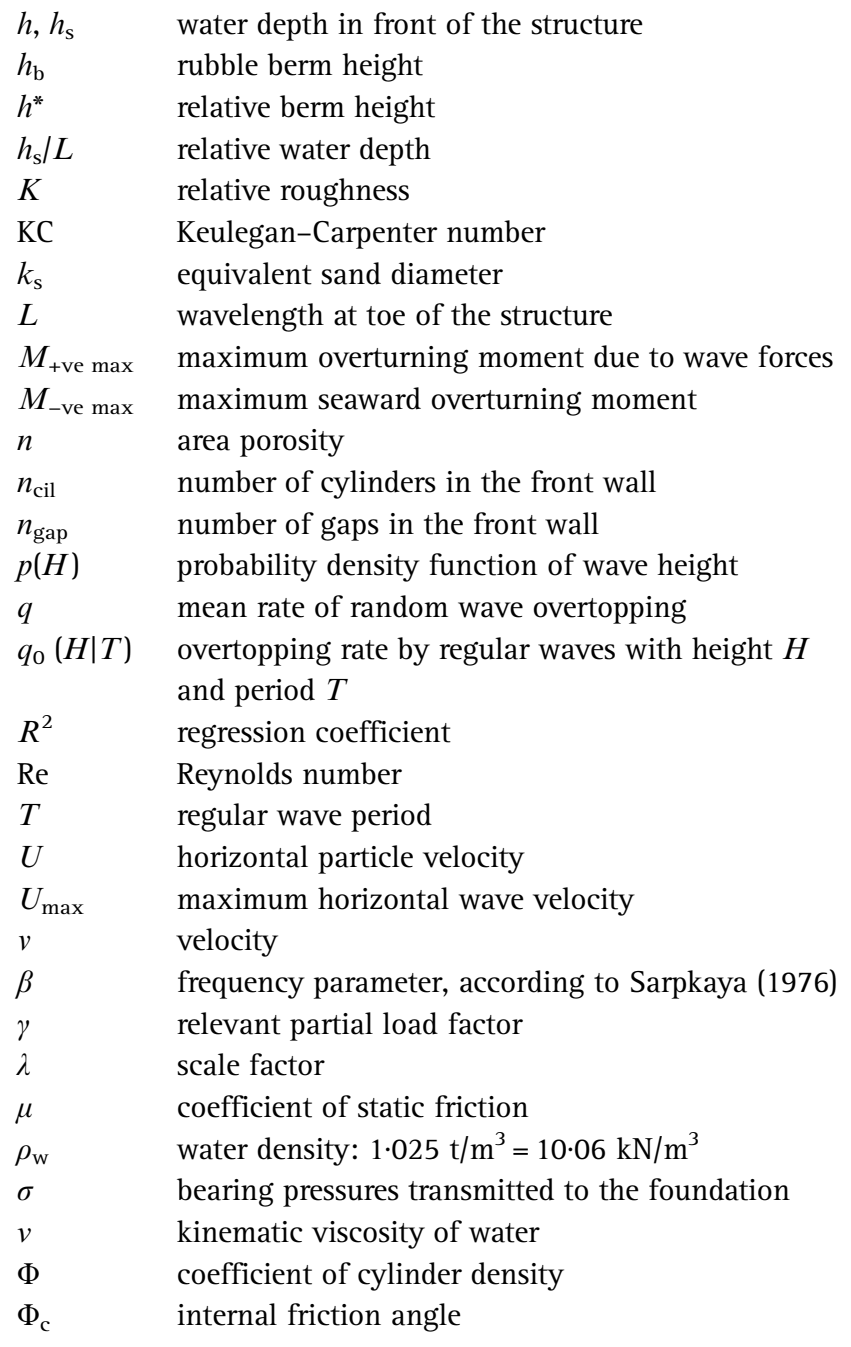

\section{Introduction}

Perforated caissons, as well as other innovative alternatives to classical vertical wall breakwaters, have been developed under different approaches over the last decades. Usually new structure types pursue reduction in wave forces, which implies, as a major advantage, lower loads transmitted to foundations. In addition, short-duration impact loads have been demonstrated in some cases as the key factor leading to breakwater failures. This fact, among others, was dealt with in the report of the International Navigation Association (Pianc) working group 28 (Pianc, 2003), where four breakwater failures (within a set of 14 existing breakwaters under study) were reported due to smaller waves than design waves.

The decrease in wave reflection is another objective, in this case for functional reasons, strongly linked with the performance of the breakwater against wave action.

Conceptually, the first endeavour is focused on the evaluation of the reduction in pressures transmitted to the foundation for a new type of caisson. This reduction is driven by two main contributions: the structure's dead weight and limited maximum wave loads.

Two main factors may be highlighted as the key design features of this new type of caisson: cylindrical geometry in the perforated front wall and a single open chamber. Derived from these features are the advantages regarding hydraulic performance: reduction in maximum wave pressures in the front wall, stepped incident wave energy dissipation (dividing the impact on the structure between front and rear walls, lagging them in time) and wave energy dissipation due to turbulence within the chamber itself.

In this paper, first, reductions in loads transmitted to the foundation are briefly summarised according to specific physical model tests. Then, the development of a new model for wave load predictions is presented. For this purpose, the results from previous reference works are taken as a starting point, in order to focus on those descriptive variables that may lead to more relevant conclusions. Potential scale effects are also discussed and evaluated and, finally, major constructive and installation constraints are identified. Thus, further minor design adaptations could be adopted to enhance the practical applicability of this new breakwater type for different locations.

\section{Brief description of the new type of caisson}

The work is based on a physical model test campaign which Dragados, S.A., the new product's owner, undertook in the Barcelona Applied Hydrodynamics Institute's (INHA) laboratory in co-operation with the Universidad Politécnica de Madrid, the Universitat Politècnica de Cataluña and the International Centre for Numerical Engineering Methods (CIMNE).

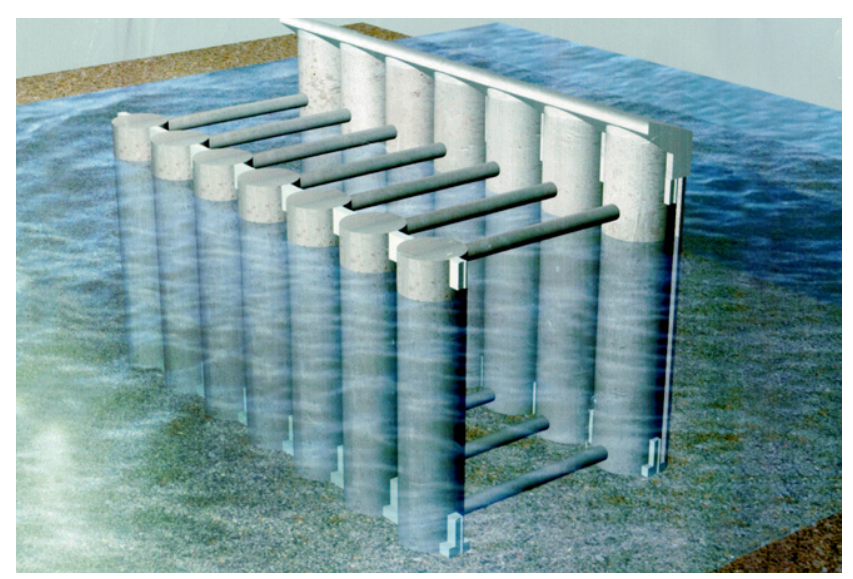

Figure 1. Conceptual picture of the caisson 
The innovative type of caisson (Figure 1) consists of two vertical, parallel, cylinder walls separated from each other, shaping a chamber between them.

As with other types of perforated caissons, the front wall is partially porous. The front cylinders are separated so that some of the incident wave energy can pass through the gaps. This wave energy is then dissipated both in the caisson chamber and on the rear wall, which is also formed by separated vertical cylinders. The rear wall may likewise be discontinuous (as the front wall) or continuous (with plane walls connecting adjoining cylinders), as is the case in the present research.

Both walls are made of reinforced hollow cylinders, which are filled with granular materials (sand or gravel). The thickness of the cylinders' walls may range from 0.40 to $0.45 \mathrm{~m}$. Indeed, the thickness may be conditioned by the filling process of the cylinders, as will be discussed later when assessing the construction constraints. The cylinders are closed at the bottom and top ends with $2 \cdot 00 \mathrm{~m}$ thick mass concrete plugs.

Every cylinder is braced at the top and bottom against the cylinder of the opposite wall. So the distance between centre lines of adjoining cylinders must therefore be the same in both walls. In addition, all the cylinders in the front wall must be braced at top and bottom. The top and bottom tie beams connecting the cylinders can be prefabricated (prestressed concrete beams) but they may also be constructed and connected to cylinders during the caisson fabrication.

Caissons must have a modular design to be manufactured with the current construction techniques. Specifically, the caisson can be adapted to be built in a floating dock with a sliding formwork technique. Caissons with seven front and seven rear cylinders have been constructed under such conditions, with a distance of $7 \mathrm{~m}$ between the centres of adjacent cylinders in both walls, so the total length of the caisson is close to $49 \mathrm{~m}$, since the diameter of the back cylinders is $6.25 \mathrm{~m}$. This is compatible with the capacities of the majority of current floating docks. However, the caisson width, which is a major parameter in hydraulic performance since it defines the dimension of the chamber, is also highly constrained by the usual capacities of floating docks, and it has been taken into account in the model tested.

This is a complex system and so effort should not be focused on seeking an absolute optimum but on a validation of the new type, identifying the most influential variables. For this purpose, initial values were adopted within the usual ranges for key geometrical parameters according to scientific literature, mainly the works by Takahashi (2002) and Takahashi et al. $(1991,1994)$ and those referred to by Oumeraci et al. (1998) in the European Union 'Proverbs' project. Owing to the specific design based on cylindrical elements, some concepts will be specifically adapted. First the 'coefficient of cylinder density' $(\Phi)$ of the front perforated wall can be defined as follows

$$
\text { 1. } \Phi=\frac{n_{\mathrm{cil}} D}{\left(n_{\mathrm{cil}} D\right)+\left(n_{\mathrm{gap}} G\right)}
$$

where $D$ is the cylinder's diameter in the front wall, $G$ is the width of the gap between adjoining cylinders in the front wall, $n_{\text {cil }}$ is the number of cylinders in the front wall and $n_{\text {gap }}$ is the number of gaps in the front wall. This factor is equivalent to the wall density concept, complementary of wall porosity $(n)$ for perforated caissons. So for the sake of clarity, $\Phi$ is used here instead of $(1-n)$, noting also that it refers to cylindrical and not plane geometry.

Another reason for the use of this density concept $\Phi$ instead of the classical porosity is due to the evaluation of the blockage effect of the structure as it is dealt with by Chakrabarti (1994) in the discussion of scale effects in the Appendix at the end of the paper, in order to be consistent with other existing studies on the influence of a group of vertical cylinders.

Thus, the front wall was tested with three different cylinder diameters: $5.00,4.70$ and $4.50 \mathrm{~m}$, in order to evaluate the influence of the gaps' width on wave loads. Thus, $\Phi$, defined according to Equation 1, ranged from 0.64 to 0.71 (i.e. equivalent values from $0 \cdot 36$ to $0 \cdot 29$ of the porosity concept for perforated vertical walls).

The back cylinders were predesigned with a diameter of $6.25 \mathrm{~m}$, with $0.75 \mathrm{~m}$ wide vertical walls connecting adjoining cylinders. The chamber width $(B)$ has ranged from 14.98 to $15.32 \mathrm{~m}$, performing as a large space for wave energy dissipation. There are two main reasons for this chamber width range. First, it is compatible with the usual floating docks' capacities for the construction of caissons; second, the rate $B / L$ (relative chamber width) is in the range $0 \cdot 10<B / L<0 \cdot 20$. Values of $B / L$ close to 0.20 have been proved to be around the optimum for reducing wave loads and reflection coefficient in front of the structure in other tests - both with regular and irregular waves - for perforated caissons with single- or multichamber systems. Ijima et al. (1976) have shown a minimum of reflection coefficient when $B / L$ is close to $0 \cdot 20$, as was also proved by Sawaragi and Iwata (1978) and by Tanimoto and Yoshimoto (1982). Allsop (1995) evaluated the performance of the reflection coefficient in a wide range of $B / L$, for porosities ranging from 14 to $28 \%$, a single chamber and a solid back wall, resulting in the lowest reflection coefficients at $B / L \approx 0 \cdot 25$, while the highest reflections are expected at $B / L \approx 0 \cdot 50$. Bergmann and Oumeraci (2000) compared both reflection coefficients and loads transmitted to the structure for single- and multi-chamber caissons and different wall porosities, finding 
that multi-chamber caissons are more efficient at reducing wave reflection than single-chamber caissons for a wider range of wave periods, and minimum values of reflection coefficient and wave loads when $B / L$ is close to $0 \cdot 20$. Zhu and Chwang (2001) developed physical model tests with regular waves in order to validate their analytical models, and the results showed a minimum value of reflection coefficient for $B / L$ close to $0 \cdot 20$, increasing as the immersion of the front wall decreased. Kirca and Kabdasli (2009) tested a perforated caisson with two chambers divided by a horizontal diaphragm, with different porosities of the front wall and with regular and irregular wave series, showing that this type of caisson can lead to a reduction in wave forces up to $30-40 \%$ when $0 \cdot 20<B / L<0 \cdot 30$. The aforementioned are listed just to provide some relevant examples. On the other hand, cases where $B / L$ values are close to $0 \cdot 10$ also need evaluation because they may be bound by constructive capacity constraints.

The caisson's foundation level was $-20.00 \mathrm{~m}$, with sea water level (SWL) at $\pm 0.00 \mathrm{~m}$; it was placed on a $2.00 \mathrm{~m}$ thick embankment. The embankment extension in front of the caisson was $6.00 \mathrm{~m}$ wide while the seabed level was modelled at $-22 \cdot 00 \mathrm{~m}$.

Finally, the crown wall is located above the rear wall being the crest freeboard $+8.40 \mathrm{~m}$, while the top of the front cylinders is at $+3.00 \mathrm{~m}$.

\section{Test methods}

\subsection{General description}

The instrumentation system was designed to record not only peak spatial pressure distributions on the different surfaces of the structure but also load time and duration distributions (impact rise time and load duration). Therefore, extreme care was taken in measuring phase lags between forces (horizontal and vertical).

Tests were undertaken at the INHA's wave flume (two dimensional) in Barcelona, applying the Froude similarity for a scale of 1:25. The flume bathymetry had a single slope of 1:67. In the following, inputs and results are presented in prototype terms unless otherwise stated.

Tests were performed in a $52 \mathrm{~m}$ long, $1.8 \mathrm{~m}$ wide, $2 \mathrm{~m}$ deep flume equipped with a piston-type wave generator. During the tests, water depth at the paddle was 1.50 and $0.88 \mathrm{~m}$ in front of the breakwater's model (so water depth is $22 \mathrm{~m}$ for the prototype). The maximum non-breaking wave that can be generated is $0.60 \mathrm{~m}$ at model scale $(15.00 \mathrm{~m}$ at prototype scale) for the range of tested wave periods. Wave absorption systems were placed at both the rear of the actuator and at the front of the flume. The Awasys software (Aalborg University) was used both for wave generation and real-time absorption of reflected waves.
The model was instrumented with 24 pressure sensors fitted at different points on the structure, apart from two load cells at the base of two of the cylinders (one front and one back) facing each other. These cells are able to measure horizontal and vertical forces while pressure sensors are used to determine wave pressure distributions along the cylinders. The overtopping was measured by installing collector chutes behind the rear wall (Figures 2 and 3).

\subsection{Test wave conditions}

Waves generated were regular in order to be able to analyse parametrically the hydraulic performance.

For the first stage $\left(D_{\text {front }}=5.00 \mathrm{~m}\right)$, a total of seven regular wave heights $(H)$ were tested between 4.0 and $11.6 \mathrm{~m}$ in a prototype $(0 \cdot 16-0.46 \mathrm{~m}$ in a model) and periods between 7.5 and $12.5 \mathrm{~s}$ $(1.5-2.5 \mathrm{~s}$ in a model $)$. In the second phase $\left(D_{\text {front }}=4.50\right.$ and

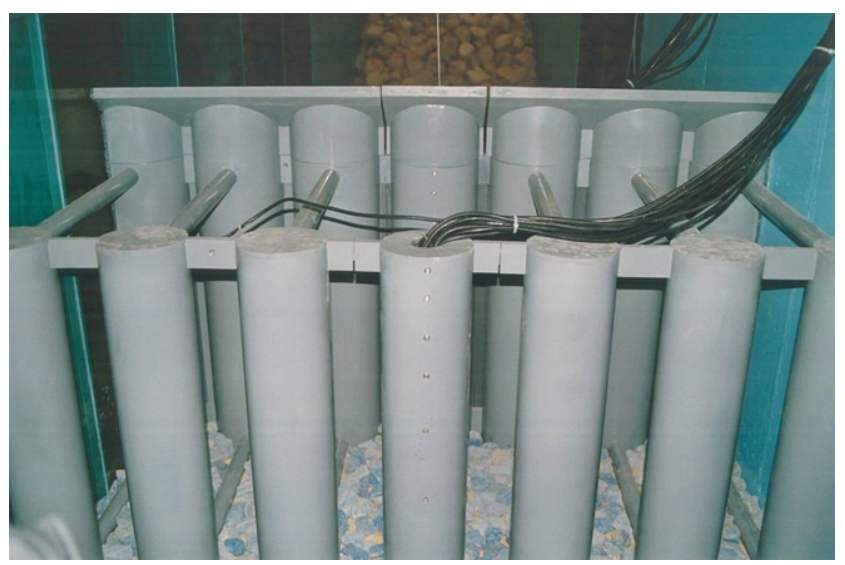

Figure 2. Test model: front view

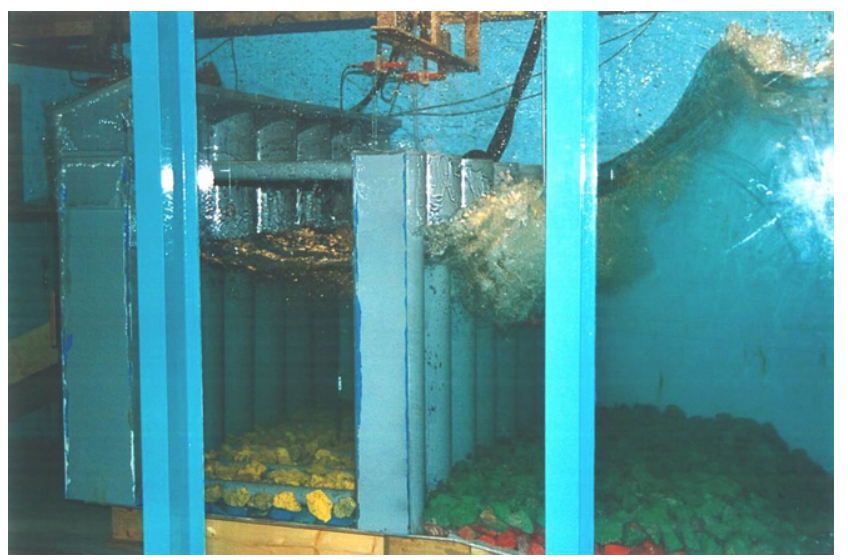

Figure 3. Test performance 


\begin{tabular}{lllll} 
Parameter & $\begin{array}{l}\text { Parameter } \\
\text { definition }\end{array}$ & $\begin{array}{l}\text { Value range } \\
\text { tested }\end{array}$ & $\begin{array}{l}\text { Situation according } \\
\text { to 'Proverbs' }\end{array}$ & $\begin{array}{l}\text { Type of wave loading in vertical } \\
\text { breakwaters according to 'Proverbs' }\end{array}$ \\
\hline Relative berm height & $h^{*}=h_{\mathrm{b}} / h_{\mathrm{s}}$ & 0.09 & $\begin{array}{l}h^{*}<0.30 \\
0.18 \leq H^{*} \leq 0.35 \text { : small waves }\end{array}$ & $\begin{array}{l}\text { Vertical breakwater } \\
\text { Quasi-static wave loads } \\
\text { Relative wave height }\end{array}$ \\
$H^{*}=H_{\mathrm{s}} / h_{\mathrm{s}}$ & $0.18 \leq H^{*} \leq 0.56$ & $\begin{array}{l}0.35 \leq H^{*} \leq 0.56 \text { : large waves } \\
\text { Impact loads }\end{array}$ \\
Relative berm width & $B^{*}=B_{\mathrm{eq}} / L$ & $0.05 \leq B^{*} \leq 0.09$ & - & -
\end{tabular}

Table 1. Type of wave loadings during the tests

$4.70 \mathrm{~m}$ ), a total of five wave heights were tested between 6 and $11.5 \mathrm{~m}$ in a prototype (between 0.24 and $0.46 \mathrm{~m}$ in a model), and periods between 7.5 and $12.5 \mathrm{~s}$ in a prototype $(1.5-2.5 \mathrm{~s}$ in a model).

Wave conditions were chosen to avoid plunging breaker conditions, as shown in Table 1. Thus, it is possible to assess the performance of the new solution compared with a conventional vertical breakwater in the same location with classical models: Goda (1985) for positive forces and McConnell et al. (1999) or Sainflou (1928) for negative (seaward) forces.

That is, the wave conditions tested would correspond to quasistatic wave loads since regular wave conditions have been modelled. Accordingly, hereafter, predictive models based on quasi-static wave loads on vertical breakwaters are used for comparison. In any case, there were a number of series with $H_{\text {reg }} / h_{\mathrm{s}} \geq 0 \cdot 50$, and indeed short-duration impact loads were recorded in some cases.

\section{Test results}

\subsection{Overtopping results}

As described by Pullen et al. in the Eurotop manual (EurOtop, 2007), wave overtopping is a dynamic, discontinuous process and it is primarily governed by individual wave heights relative to the crest freeboard of the seawall.

Since these tests have been carried out with regular waves, and commonly accepted overtopping models are developed from random waves, it is necessary to 'translate' the results from the regular pattern to the equivalent situation with irregular waves.

When a set of laboratory records on the rate of overtopping $q_{0}$ by regular waves with various combinations of heights and periods is available, an approximate value of the mean rate of random wave overtopping $(q)$ can be estimated with the following formula by Goda (2010)

2. $q \approx \int_{0}^{\infty} q_{0}(H \mid T) p(H) \mathrm{d} H$ where $q_{0}(H \mid T)$ is the overtopping rate by regular waves with height $H$ and period $T ; p(H)$ is the probability density function of wave height.

As regards the probability density function, the Rayleigh distribution can be used. According to Goda (2010), Equation 2 gives reasonably good approximations compared with the results of direct measurements with irregular waves in the laboratory for vertical walls in intermediate and deep waters, resulting in every case that $q>q_{0}$, as was first evaluated in experimental tests by Paape (1960). This approach is only valid when the influence of wave period between different situations is small or negligible.

In Figure 4, tests' overtopping results are shown for two scenarios of the front cylinder diameters. These overtopping values have been modified according to Equation 2 in order to show the equivalent values for random waves. Furthermore, the results should be considered for estimation purposes only since the different wave heights were tested with different periods, and therefore the equivalence may not be very accurate.

The initial crest freeboard relative to SWL was $+8.40 \mathrm{~m}$. The overtopping rates have been compared with those predicted

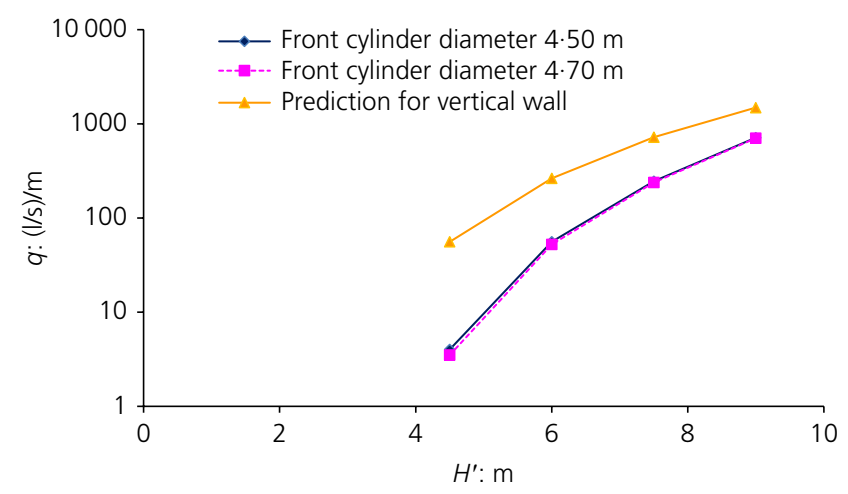

Figure 4. Overtopping comparison. Crest freeboard relative to $\mathrm{SWL}+8.40 \mathrm{~m}$ 
by Franco's model (Franco \& Franco, 1999) for vertical wall breakwaters and the same crest level.

For the equivalence of wave heights, $H_{\text {reg }}=H=H^{\prime}$ was adopted (in which $H$ is the regular wave height in tests; $H^{\prime}$ is the arithmetic mean wave height of the storm) and the usual relations between representative wave heights according to the Rayleigh distribution

3. $H_{\mathrm{s}} \approx 1.60 H^{\prime}$
$F 1_{\mathrm{h}+\mathrm{ve}}+F 2_{\mathrm{h}-\mathrm{ve}}$ and vice versa, corresponding to maximum compressive and tensile stresses in the top connection beams between front and rear cylinders. This issue is not addressed in this paper since it has no geotechnical implications.

It is worth mentioning that horizontal wave loads and moments were measured by the load cells fitted, respectively, at the base of the front and rear central cylinders and checked by the approximate integration of records of pressure sensors along the cylinders at every instant.

The worst configuration regarding maximum wave forces and moments was the case with $D_{\text {front }}=4.50$ and $2.50 \mathrm{~m}$ gaps between adjacent cylinders. Additionally, wave forces were recorded in three different configurations regarding the front tie beam at the top of the cylinders: at $+3.00 \mathrm{~m}$, at $-6.00 \mathrm{~m}$ and with no front tie beam. The influence of this element of the design is considered later in Equation 7.

An approximate comparison with a conventional caisson is made, using Goda (1985) and Sainflou (1928) models for positive and seaward forces, respectively.

Other equivalences could be used for this comparison, for example $H_{\text {reg }}=H_{\mathrm{s}}$ or $H_{\text {reg }}=H_{\text {max }}$. In these cases, the resulting values of $q$ would be modified both in the estimation of equivalent random wave overtopping for this perforated caisson and also for the vertical type because the input values of $H_{\mathrm{s}}$ for Franco's formula should be modified accordingly. So these results should be considered for relative comparison purposes only rather than for an accurate quantitative evaluation of overtopping rates (Figure 4).

To obtain random waves' overtopping rates of the same order of magnitude according to the procedure described above, the crown wall height for vertical breakwaters should be around +15 m level.

\subsection{Comparative summary of wave loads and bearing pressures transmitted to the foundation}

The following results were drawn up on the basis of measuring wave forces at design critical instants, which correspond with the maximum horizontal wave forces both in the wave direction $\left(F_{\mathrm{h}+\text { ve max }}\right)$ and the seaward direction $\left(F_{\mathrm{h}-\mathrm{ve} \text { max }}\right)$. Similarly, maximum overturning moments in both directions are shown. Although maximum horizontal forces and maximum moments do not happen exactly at the same time, this assumption is not far from the reality. Thus, adopting these values simultaneously keeps the calculation on the side of safety, since this involves maximum eccentricity and, thus, pressures transmitted to the foundation.

There are other critical instants regarding structural viability of the caisson, which are those with maximum values of
The same caisson foundation level $(-20 \cdot 00 \mathrm{~m})$, embankment extension in front of the structure $(6.00 \mathrm{~m})$ and seabed level $(-22.00 \mathrm{~m})$ are supposed for comparison of both types. For the vertical type, a $26.00 \mathrm{~m}$ wide caisson is adopted with crown wall top at $+15.00 \mathrm{~m}$, which has been proved as the freeboard for similar random wave overtopping rates.

Figures 5-8 correspond to the aforementioned design critical instants (Tables 2 and 3 ).

\subsection{What arises from these results?}

The results have shown a consistent pattern at the comparison of loads with conventional vertical walls, and evaluation of

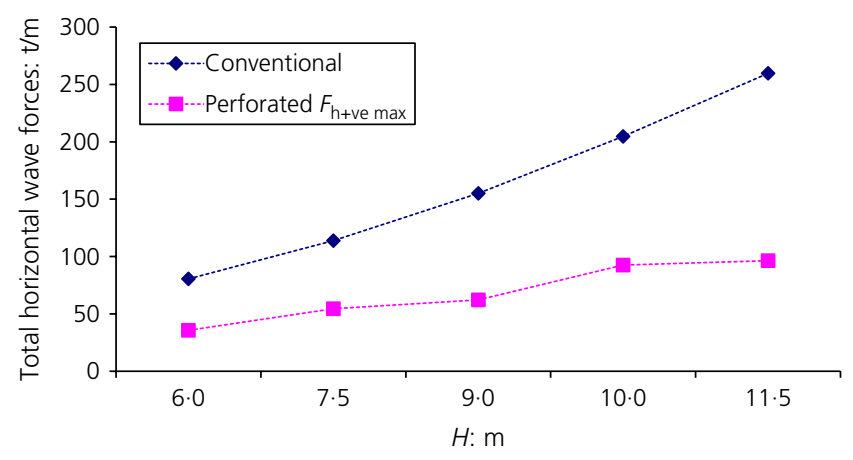

Figure 5. Comparison of maximum horizontal wave forces on the structure 


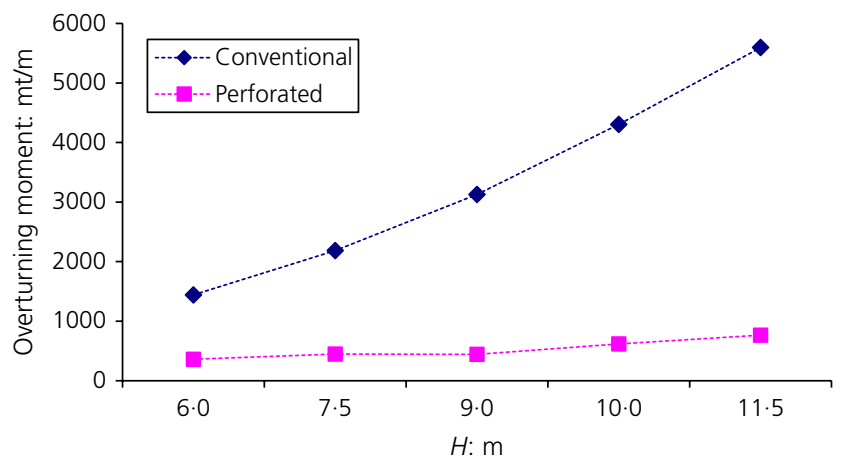

Figure 6. Comparison of maximum moments on the structure

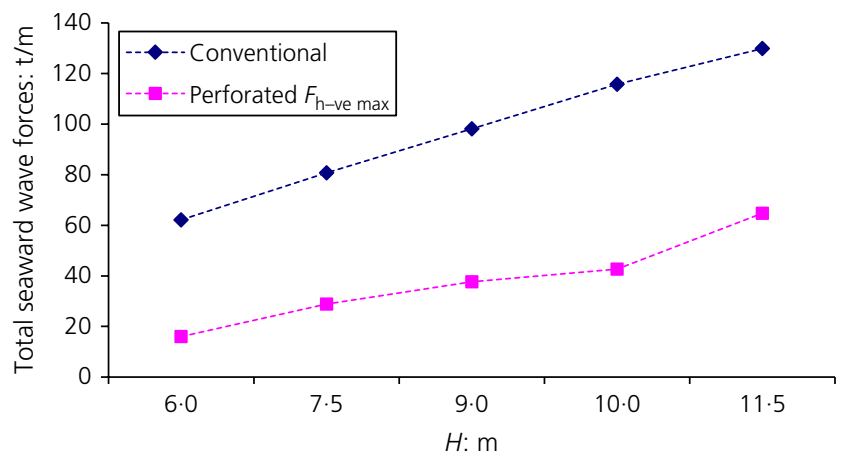

Figure 7. Comparison of maximum seaward wave forces on the structure

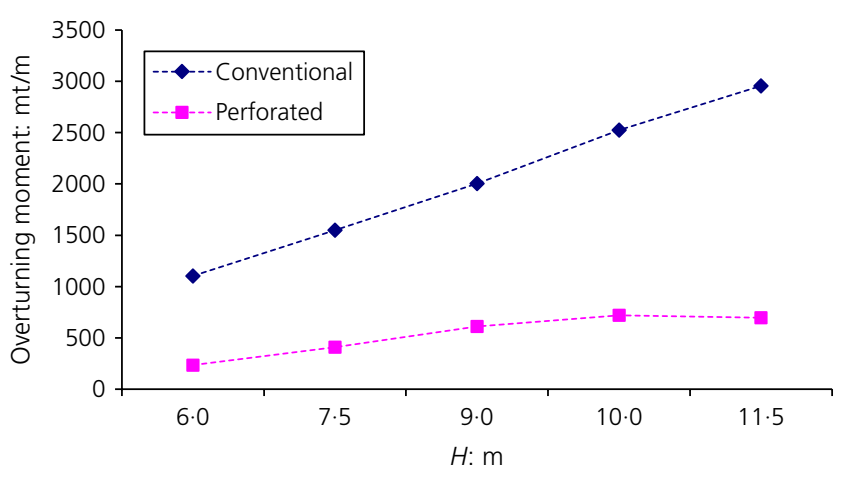

Figure 8. Comparison of maximum seaward moments on the structure

practical consequences is first based on the assessment of relations between maximum horizontal forces in both directions: $F_{\mathrm{h}-\mathrm{ve} \max } / F_{\mathrm{h}+\text { ve } \max }$.

\begin{tabular}{lrcc}
$H: m$ & $T: s$ & $\begin{array}{c}\text { Maximum horizontal } \\
\text { wave forces: } \%\end{array}$ & $\begin{array}{c}\text { Maximum } \\
\text { moments: \% }\end{array}$ \\
\hline $6 \cdot 0$ & $7 \cdot 5$ & 56 & 75 \\
$7 \cdot 5$ & $8 \cdot 5$ & 52 & 80 \\
$9 \cdot 0$ & $9 \cdot 5$ & 60 & 86 \\
10.0 & $11 \cdot 5$ & 55 & 86 \\
11.5 & $12 \cdot 5$ & 63 & 86
\end{tabular}

Table 2. Reduction (\%) of maximum horizontal forces and moments on the structure

\begin{tabular}{lrcc}
\hline$H: m$ & T: s & $\begin{array}{c}\text { Maximum seaward } \\
\text { horizontal wave forces: \% }\end{array}$ & $\begin{array}{c}\text { Maximum seaward } \\
\text { moments: \% }\end{array}$ \\
\hline $6 \cdot 0$ & $7 \cdot 5$ & 74 & 79 \\
$7 \cdot 5$ & $8 \cdot 5$ & 64 & 74 \\
9.0 & $9 \cdot 5$ & 62 & 70 \\
10.0 & 11.5 & 63 & 71 \\
11.5 & 12.5 & 50 & 76
\end{tabular}

Table 3. Reduction (\%) of maximum seaward forces and moments on the structure

From the analysis of this parameter, major differences are raised in the performance referred to in 'Proverbs' for vertical breakwaters: in the case of conventional caissons, for relative depths $h_{\mathrm{s}} / L<0 \cdot 25$, negative (net seaward) forces may be higher than positive (net landward) forces for most wave steepnesses; for small relative wave heights $\left(H_{\mathrm{s}} / h_{\mathrm{s}}<0 \cdot 3\right)$, there is a small possibility that negative forces may exceed positive forces $\left(F_{\mathrm{h}-\text { ve max }} / F_{\mathrm{h}+\text { ve max }}>1\right)$. While this situation occurs for the majority of the cases, in deeper water conditions, $H_{\mathrm{s}} / h_{\mathrm{s}}<0 \cdot 2$.

However, that pattern does not occur for this perforated type of caisson, where positive forces are greater than seaward forces in almost all cases tested (Figure 9), regardless of the value of the $H / h_{\mathrm{s}}$ parameter.

Viewing the results in terms of reduction in forces and moments compared with a conventional caisson, the capacity of the structure to resist sliding needs to be evaluated, since the dead weight of this type of caisson is also much smaller. For example, for a $49 \mathrm{~m}$ long caisson of this new type, the resulting dead weight is slightly $>19000 \mathrm{t}$ (including reinforced concrete and fill inside the cylinders). In addition, the dead weight of the crown wall is close to $3250 \mathrm{t}$, so it results in a dead weight of some $22350 \mathrm{t}$ and some $455 \mathrm{t} / \mathrm{m}$. This means a significant reduction in stabilising loads compared with a conventional massive caisson (with a total dead weight of some 


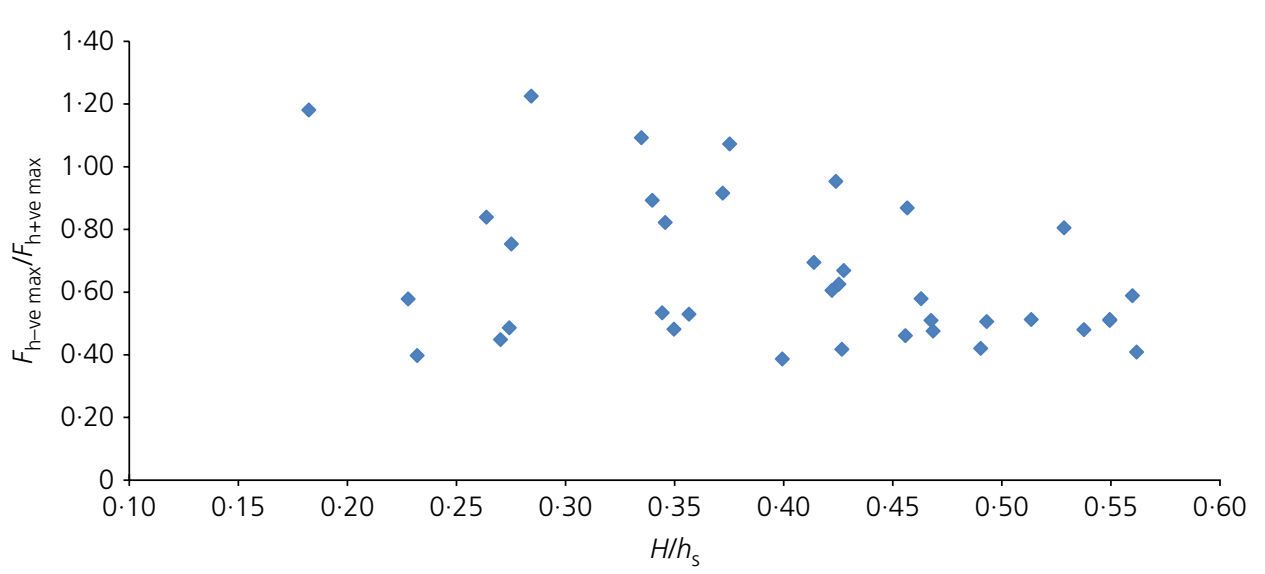

Figure 9. Relation between $F_{\mathrm{h}-\mathrm{ve} \max }$ and $F_{\mathrm{h}+\mathrm{ve} \max }$

$56000 \mathrm{t}$ during service life, including all the elements) and therefore sliding resistance evaluation is needed initially to validate the viability of this solution.

The Spanish Recomendaciones Geotécnicas para Obras Marítimas y Portuarias (ROM) standard (Puertos del Estado, 2005) establishes the sliding evaluation according to the resulting sliding safety factor $\left(F_{\text {slid }}\right)$, defined as

$$
\text { 5. } \quad F_{\text {slid }}=\mu \frac{\Sigma V}{\Sigma H}
$$

where $\mu$ denotes the coefficient of static friction between the caisson and the embankment, with $\mu=\operatorname{tg}\left(\Phi_{\mathrm{c}}\right)$ and $\Phi_{\mathrm{c}}$ being the internal friction angle within the contact surface. In addition, in Equation $5 \Sigma V$ and $\Sigma H$ represent the total vertical and horizontal design loads (i.e. the characteristic values have been multiplied by their relevant partial load factor $\gamma$ ).

According to the maximum wave loads recorded during the tests and assuming $\mu=\operatorname{tg}\left(32^{\circ}\right)=0.62$, the sliding safety factor for this new type of caisson results in $F_{\text {slid }}=1.41$ (greater than the minimum prescribed by ROM standard, which is $1 \cdot 30$ ). In addition, for the characteristic values of the loads, $\Sigma H / \Sigma V=0 \cdot 25<0 \cdot 40$, which is another usual requirement in other standards for sliding resistance evaluation in gravity base foundations.

Finally, in the initial calculations, an analytical estimation of maximum bearing pressures transmitted to the foundation $(\sigma)$ is included below, in order to validate whether this breakwater type actually represents a major reduction in this regard, both for wave direction (+ve) and seaward (-ve) direction.

\begin{tabular}{ccc}
\hline$H / h$ & + ve: $\%$ & - ve: $\%$ \\
\hline 0.27 & 37 & 44 \\
0.34 & 42 & 45 \\
0.41 & 50 & 45 \\
0.45 & 54 & 48 \\
0.52 & 58 & 53
\end{tabular}

Table 4. Reduction (\%) of maximum bearing pressures $(\sigma)$ transmitted to the foundation

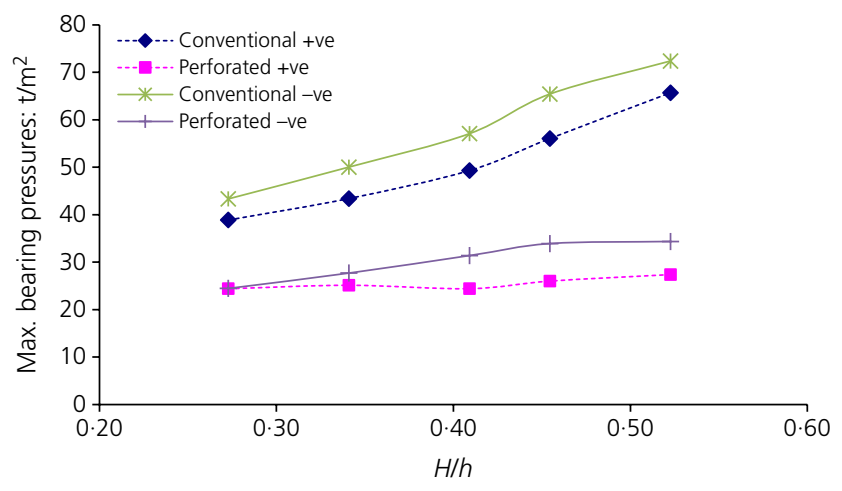

Figure 10. Comparison of maximum bearing pressures transmitted to the foundation

A summary of the comparison with respect to a vertical breakwater solution is included in Table 4 and Figure 10. The results are shown with reference to the dimensionless 
parameter $H / h$. Similarly to the sliding evaluation, all the loads are included in the calculation of bearing pressure, not just the contribution of wave actions.

To conclude, the reductions in wave loads on the structure lead to significant reductions of pressures transmitted to the foundation, while this fact does not undermine the capacity of the structure to resist sliding.

The results are consistent and show a regular pattern in terms of horizontal wave forces, moments and loads transmitted to foundations, both for positive and seaward directions.

\section{What are the proper tools to predict the performance of this new type of caisson?}

The obvious difference of this new type of caisson leads to substantial deviations of loads compared with vertical breakwaters. Related to cylindrical geometries, Morison et al. (1950) established the calculation model of wave forces on isolated cylinders. This formula and all of the models derived from the work of Morison et al. (1950) - Chakrabarti (1994, 2005), Keulegan and Carpenter (1958), Ochi and Tsai (1984), Sarpkaya (1976) and Sarpkaya and Isaacson (1981) - are applicable to isolated vertical cylinders or groups of cylinders, but they do not deal with the case of a breakwater with a chamber. So they seem not to be directly applicable to predict total wave forces on this new type of breakwater and thus, a new parametric experimental approach is needed. However, they need to be taken into account to assess some potential scale effects, as discussed later.

For studies in specific locations, preliminary analysis must be carried out in terms of a set of governing parameters but also based on constructability constraints. The final design should be validated through physical model tests. Nevertheless, this study has led to a number of preliminary conclusions that are useful for potential applications of this breakwater type.

The first point is the definition of the domain in which the tests were carried out, in terms of three key parameters: the coefficient of cylinder density $(\Phi)$, the relative wave height $(H / h)$ and the relative chamber width $(B / L)$.

For these tests $\Phi$ ranged from 0.64 to $0 \cdot 71$. According to Akilly et al. (2004), for $\Phi \leq 0.5$ it may be deemed that the front cylinders no longer interact, leading to a significant increase of the incident energy in the rear wall in that situation, losing some of the benefits of the solution. Conversely, high values of $\Phi$ can cause a blockage effect (produced by the mass of water 'retained' in front of the caisson), increasing wave loads in the front perforated wall.

Regarding the performance in terms of relative wave height, Figure 11 shows the maximum horizontal loads for this perforated caisson normalised by those from an equivalent conventional caisson previously described, similar to that of Takahashi et al. (1991) for perforated vertical walls. For every case in the present work, $d^{\prime} / d=1.00$ and $d / h=0.91$. The reductions, in terms of the rate in maximum horizontal wave loads between the present perforated caisson $\left(F_{\text {inn }}\right)$ and conventional vertical wall $\left(F_{\text {conv }}\right)$, are larger than those evaluated by Takahashi et al. (1991) for other perforated caisson types. Here it is about 0.40, while this rate in the tests of Takahashi et al. (1991) ranged approximately from $0 \cdot 80$ to $0 \cdot 60$.

The performance tends to be similar for the wide range of $H / h$ values tested, typically from $0 \cdot 15$ to 0.55 (Figure 11).

Additionally, a similar pattern occurs in terms of the dimensionless parameter $B / L$, which ranged approximately from $0 \cdot 10$ to $0 \cdot 20$ in this study (Figure 12 ).

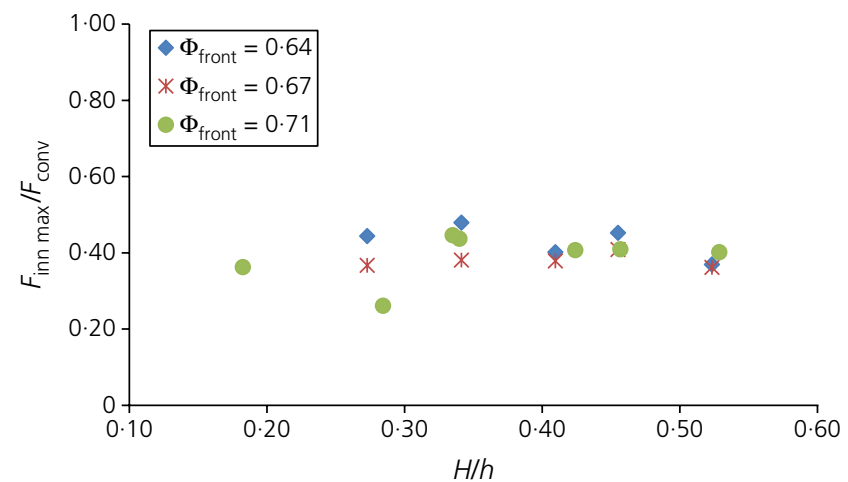

Figure 11. Maximum wave force rates between the innovative and conventional vertical wall caissons

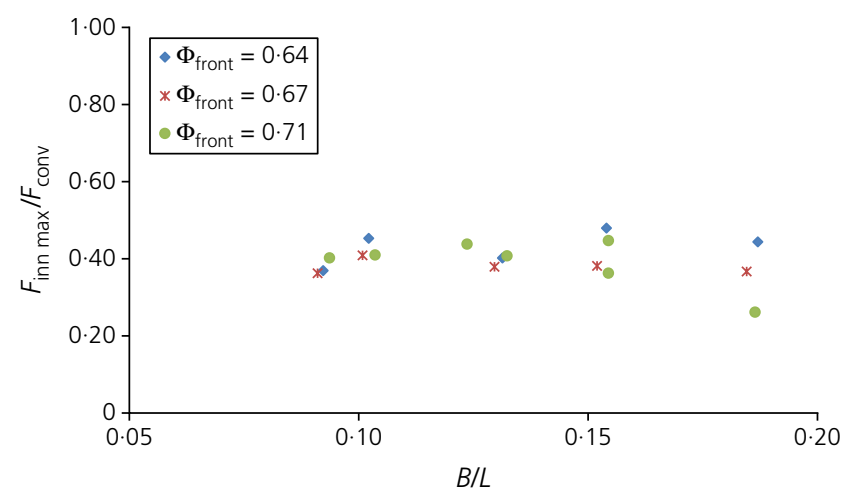

Figure 12. Maximum wave force rates between the innovative and conventional vertical wall caissons in terms of $B / L$ 
In conclusion, when $H_{\mathrm{D}} / h<0 \cdot 55$, a rate of $B / L \approx 0 \cdot 15$ will lead to a reduction in maximum wave forces according to $F_{\text {inn }} / F_{\text {conv }} \approx 0 \cdot 40$. Regarding the comparison in bearing pressures transmitted to foundations with respect to a conventional caisson, results are shown in Table 4 and Figure 10, with larger differences between types as the incident wave height increases. Thus, while in the absence of waves the reduction in pressures transmitted to the foundation is about $25 \%$, the reduction is above $50 \%$ for the higher storm waves tested.

Once the ranges of the key parameters have been defined, the next step is the identification of the variables that may govern total positive wave forces. One principal variable has been detected for this purpose: the incident wave energy per unit length $\left(E^{\prime}\right)$, described as

$$
\text { 6. } E^{\prime}=\frac{\rho g}{2}\left(\frac{H}{2}\right)^{2} L
$$

In a formal way, $E^{\prime}$ is expressed in $\mathrm{kJ} / \mathrm{m}$ when $\rho g$ is entered in $\mathrm{kN} / \mathrm{m}^{3}$. Furthermore, the second expression in Equation 6 can also express a force in $\mathrm{kN}$, and be used as a descriptive variable of the wave forces against the cylinders.

To be scaled with the width of the structure and obtain the forces per unit length, the second expression in Equation 6 needs to be affected by a factor $1 / D_{\text {front }}$ ( $D_{\text {front }}$ being the diameter of the front cylinders). In addition, the wave energy term needs to be affected by another correction factor which, in turn, depends on two dimensionless variables: $H_{\mathrm{i}} / h$ and $B / L$. These factors have exponential adjustments according to the test results. So the resulting model shows a predictive performance as shown in Figure 13, which conforms to a model as follows

$$
\text { 7. } F_{\text {calc }}(\mathrm{kN} / \mathrm{m})=a \frac{1}{D_{\text {front }}} \frac{\rho \boldsymbol{g}}{2}\left(\frac{H_{\mathrm{i}}}{2}\right)^{2} L \mathrm{e}^{\left(b \cdot H_{\mathrm{i}} / h+c B / L\right)}
$$

The values of $a, b$ and $c$ factors depend on the configuration of the tie beam which braces the front cylinders against each other at the top of the caisson. This beam is needed for structural reasons, but its elevation with reference to the water level may be decided by the designer.

As explained previously, three configurations of this front beam were tested. Assuming in Equation 7 that $\rho g=10.06 \mathrm{kN} / \mathrm{m}^{3}$, then $a, b$ and $c$ factors are as shown in Table 5 according to the test results.

The values of $a, b$ and $c$ factors from Table 5 reflect some variation with the elevation of the front tie beam, while these values are completely different when the beam is not installed.

Nevertheless, Equation 7 shows a similar performance for the three cases. Figure 13 shows the results and tendency lines of adjustment for each case when the model is compared with the test results.

The previous model can be used for predesign purposes in cases where $\Phi$ (or the porosity) of the front wall is within the range of these tests.

Finally, the analysis for irregular waves would remain homogeneous with the aforementioned Equation 7, simply by using

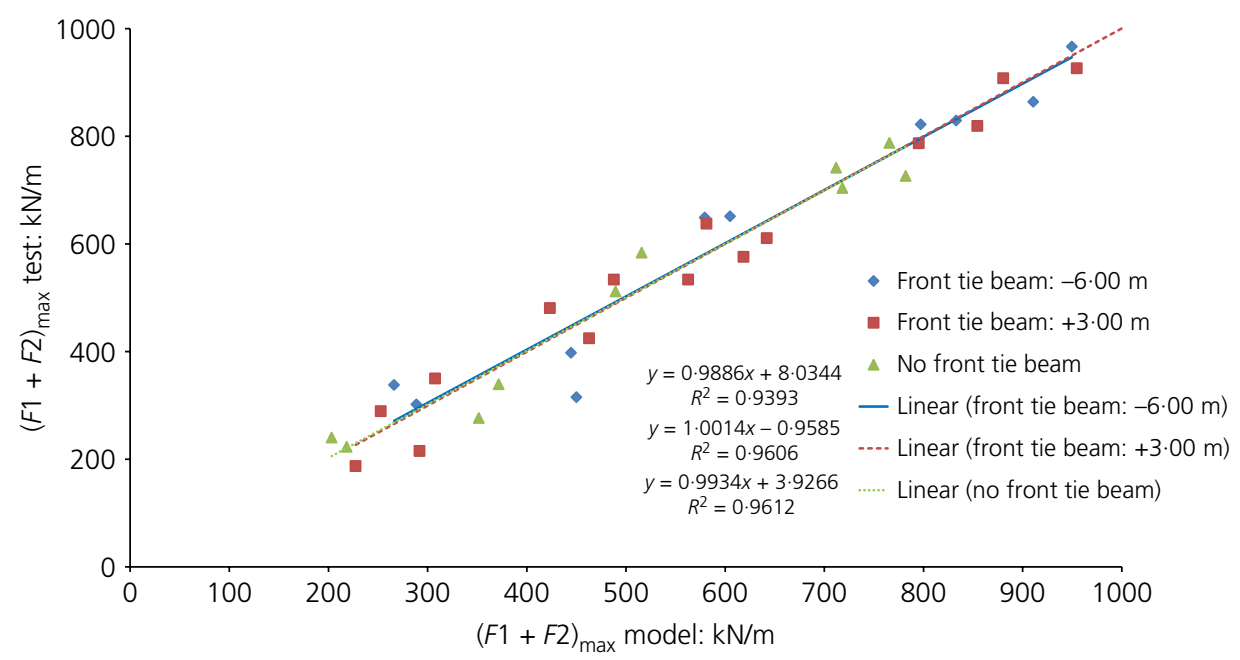

Figure 13. Performance of the proposed $F_{\text {calc }}$ predictive model 


\begin{tabular}{lrcr} 
Elevation of the front tie beam* & \multicolumn{1}{c}{$a$} & $b$ & $c$ \\
\hline-6.00 & 1.26 & -3.77 & -1.41 \\
+3.00 & 1.43 & -3.90 & -1.47 \\
No tie beam & 12.94 & -6.81 & -10.88
\end{tabular}

*Still water level at $\pm 0.00 \mathrm{~m}$

Table 5. Factors $a, b$ and $c$ as a function of the configuration of the front tie beam at the top of the cylinders

$H_{\mathrm{d}}=\min \left(H_{1 / 250}, H_{\mathrm{b}}\right)$ instead of $H_{\mathrm{i}}$. However, in that case, values of factors $a, b$ and $c$ would need to be evaluated again.

\section{Discussion of potential scale effects}

Pressure law distribution (and therefore resulting forces) along a vertical slender cylinder subjected to a steady flow depends on the Reynolds number (Re), defined as

8. $\operatorname{Re}=\frac{U D}{v}$

where $U$ is the horizontal wave velocity, $D$ is the cylinder diameter and $v$ is the kinematic viscosity of water. So due to the application of Froude's similarity, there exists a distortion in the Re between the model and the prototype.

Furthermore, the problem requires the definition of the inertia and drag coefficients $\left(C_{\mathrm{M}}\right.$ and $\left.C_{\mathrm{d}}\right)$ both for the model and the prototype, since these coefficients affect the estimation of inertia and drag forces. Thus the problem consists of the estimation of $C_{\mathrm{M}}^{\text {prot }} / C_{\mathrm{M}}^{\text {mod }}$ and $C_{\mathrm{d}}^{\text {prot }} / C_{\mathrm{d}}^{\text {mod }}$. However, complexity increases as the structure itself leads to an increase in wave height in front of the caisson, which also affects the values of $C_{\mathrm{M}}$ and $C_{\mathrm{d}}$. Furthermore, $C_{\mathrm{d}}$ and $C_{\mathrm{M}}$ show high variability in the vicinity of $\operatorname{Re} \sim 10^{5}$, which is the case of the authors' model.

In addition, there are several curves of $C_{\mathrm{d}}$ against Re as a function of the Keulegan-Carpenter number (KC, which is the rate between the orbital amplitude of the wave and the diameter of the cylinder), which were described by Sarpkaya (1976). Chakrabarti (1994) developed guidance on how $C_{\mathrm{d}}$ should be modified according to $\Phi$ variations for different values of $\mathrm{Re}$ owing to the blockage effect due to the presence of the structure. Finally, the use of relative roughness concept $(K)$, as it was defined by Nikuradse (1933), must be adapted to the authors' problem.

On the basis of what is mentioned above, the discussion of these scale effects is included at the end of the paper as an
Appendix. In conclusion, relative roughness factor $(K)$ and the variability of $C_{\mathrm{d}}$ with $\Phi$ stand as the most influential variables in the estimation of potential scale effects, in those cases where drag forces become increasingly relevant. So it is advisable to perform specific physical tests for each particular project in which similar caissons are adopted, specifically tests with large ranges of $\Phi$ and roughness.

The use of freshwater in the tests is another issue to be assessed regarding the potential scale effects, due to the difference in density and also due to the fact that air behaves differently in the model than in seawater. The latter effect is related to water aeration affecting the results in peak pressure values. Bullock et al. (2000) in the University of Plymouth have shown that the freshwater peak pressure values were about $10 \%$ higher than those for seawater. However, when the rise time of an impulse was taken into account, the impulse, or the impulsive loading, on the model breakwater was of the same order. So these scale effects do not seem to alter the tests' key conclusions significantly.

\section{Potential adaptations to key construction constraints}

The caisson is designed to be built using the floating dock construction technique (Figure 14) - that is, with the use of sliding formworks - and it has been designed to be towed and installed taking advantage of its own buoyancy conditions.

The main constraint for the construction viability is the available draught at the construction quay. The bottom slab can be continuous or not (as it is in the model tested). The former involves higher stability during buoyancy stages (towing and installation) but a larger draught is needed during fabrication. The latter slab configuration may be preferable for the following reasons.

There is sufficient safety margin for buoyancy stability if the caisson is wide enough. Buoyancy stability is evaluated in terms of metacentric height (GM) and it is usually required to be larger than $0.50 \mathrm{~m}$ (higher values can be required for some marine operations in non-sheltered areas).

- The previous requirement involves caisson widths compatible with current floating docks' capacities and also values of $B / L$ near the optimum for standard storm wave conditions.

- The dynamic uplift pressure decreases as the porosity of the bottom slab increases. In the model tested, the bottom slab is simply formed by the bottom of the cylinders (Figure 1). However, the beams at the bottom that brace one cylinder against the cylinder of the opposite wall may be modified in order to be part of the bottom slab as well. 


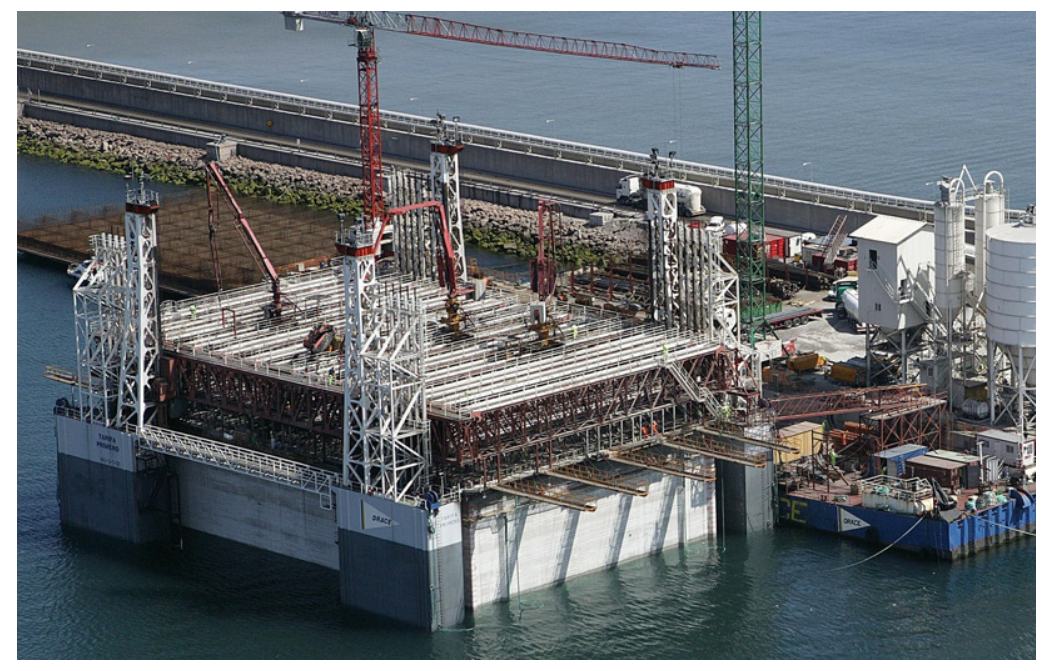

Figure 14. Construction of caissons with a floating dock (source: Dragados and DRACE)

In the case of a continuous bottom slab, uplift pressures may be relevant to stability evaluation due to the reduced weight of the caisson. In that case, it would be necessary to conform cells to be filled up to some level in order to gain enough weight, similar to conventional gravity caissons; and thus, the lower part of the shaft would be closed through the perimeter of the caisson (i.e. with connection walls between adjacent cylinders up to some level). In this case, the $d^{\prime} / d$ parameter would change from the current test conditions, where $d^{\prime} / d=1 \cdot 00$, and the wave loads could change accordingly.

In case of strong constraints in existing draughts in the construction quay, it could also be possible to use the pontoon of the floating dock's own buoyancy until caisson launching, towing the floating dock-caisson assembly to a place with higher water depths.

The tie beams and their joints to cylinders can be built within the floating dock as well, provided that beams have regular cross-sections.

Regarding installation, the caisson can be installed onto the embankment by ballasting the cylinders with seawater while the final sand ballast can be pumped hydraulically by suction dredgers or poured from trucks and loaders from the top of the caisson using temporary and movable working platforms. In the case of hydraulic filling by dredgers, the pore pressure of the filling might be too high during the start of the process. So the dredgers should pump at low flow rates, in order to adapt the filling to the internal pore pressure dissipation process. Otherwise, the cylinders' wall should be thicker for structural reasons, leading to major implications in floating conditions during the construction phase.

\section{Conclusions}

Test results for this type of caisson demonstrate a substantial improvement in load transmission to foundations. First, the reductions in maximum wave loads are larger than other nonconventional types based on perforated vertical walls. Second, there is a significant reduction of dead weight of the structure compared with a conventional gravity caisson.

The wave load results for the new type show a regular pattern when compared with conventional vertical wall breakwaters. In addition, the analysis can be simplified due to the fact that positive wave forces (seaward) are greater than negative ones for almost every value of $H / h$, which is another significant difference compared with conventional caissons.

As an initial approach to addressing the hydrodynamic complexity of the system, it is recommended to set a first range of geometrical parameters near the optimum regarding wave load reduction, according to the aforementioned reference tests for perforated caissons with a single chamber. Primarily the proposed parameters are the cylinder density parameter $(\Phi)$ and $B / L$. For breakwaters with this new type of caisson, the authors recommend adopting values of $\Phi$ in the range of $0 \cdot 65-0 \cdot 70$ and $B / L$ in the vicinity of $0 \cdot 15$, since these values also solve major construction constraints.

A new predictive model for maximum total wave loads has been proposed here as a function of incident wave energy, $B / L$ and $H / h$. 
Moreover, the possible effects of scale derived from the tests have been identified, analysed and estimated, concluding that the roughness of the cylinders is a key issue that could affect the validity of test results.

Finally, hydraulic performance allows further modifications in order to make the new type of caisson more adaptable to construction procedure constraints, while it has been designed to be built with the current floating dock facilities.

\section{Future research}

Testing under random waves and with potential impulsive load conditions would be the scope of further works. In addition, the response to oblique waves may alter some of the conditions that help in the design of breakwaters. Likewise, there remains a field of research in terms of a wider range of values of the $\Phi$ parameter, $B / L$ and $H / h$ for plunging breaker conditions. However these situations may involve an increase of $B$ (and therefore the caisson width) that exceeds the capacity of the conventional construction techniques with floating docks. In addition, these increases in the chamber width could lead to a departure from the optimum values of $B / L$ in accordance with the existing reference works.

Additionally, there could be some design adaptations to obtain better buoyancy and reduce the draught required at the construction quay, which might be a major constraint in some locations. This would imply some differences in the hydraulic performance of the caisson during service life.

\section{Acknowledgements}

The authors acknowledge the efforts of $\mathrm{Mr}$ Emilio Alonso (r.i.p.) because his approach was used as the initial conceptual approach. They also thank all the staff of Dragados S.A., INHA and CIMNE who were involved in different ways in the project. Contributions of William Allsop, Leo Franco and Chris Patterson have also been very helpful, as well as the analysis by José Luis Galmés (UPC), Pau Sánchez and Enrique Ripoll (INHA) regarding the assessment of main potential scale effects. Finally, the public Spanish Department of Industrial Technologic Development Center (CDTI) is also acknowledged for having partially funded the project and Fundación Agustín de Betancourt (Universidad Politécnica de Madrid).

\section{Appendix: Discussion of potential scale effects}

\section{A1.1 The influence of Re and drag forces}

The pressure distribution along a vertical cylinder subjected to an oscillatory flow has two terms. The first is related to the stationary flow and it is proportional to $U^{2}(t)$, with
$U(t)$ being the horizontal particle speed, while the second is an inertial term and is proportional to flow acceleration $\mathrm{d} U(t) / \mathrm{d} t$.

According to Morison et al. (1950), the first term can be described as a drag force as follows

$$
\text { 9. } \mathrm{d} F_{\mathrm{d}}=C_{\mathrm{d}}(\operatorname{Re}) \rho D \frac{U^{2}}{2}
$$

where $C_{\mathrm{d}}$ is the drag coefficient and depends on the Re. On the other hand, the second term can be described as

$$
\text { 10. } \mathrm{d} F_{\mathrm{i}}=C_{\mathrm{M}} \rho \frac{\pi D^{2}}{4} \frac{\mathrm{d} U(t)}{\mathrm{d} t}
$$

where $C_{\mathrm{M}}=2$ for a smooth cylinder and continuous potential flow.

The Re represents the rate between mass and viscosity forces and can be defined as follows for a vertical slender cylinder subjected to a steady flow

11. $\operatorname{Re}=\frac{U D}{v}$

where $D$ is the cylinder diameter and $v$ is the kinematic viscosity of water.

Owing to the application of Froude's similarity, there exists a distortion in the Re between the model and the prototype. From the dimensional analysis it can be stated as follows

$$
\text { 12. } \operatorname{Re}=\frac{F_{\text {mass }}}{F_{\text {visc }}}=\frac{\rho v^{2} L^{2}}{v L v}=\frac{v L \rho}{v}
$$

where $\rho$ is the density, $v$ the velocity, $L$ the length and $v$ is the viscosity.

The application of Froude's similarity (Froude number, $F_{\mathrm{R}}$, is the relation between mass and inertia forces) implies that

$$
\text { 13. } \frac{F_{\mathrm{R}, \text { model }}}{F_{\mathrm{R}, \text { protot }}}=1 \Rightarrow n_{\mathrm{FR}}=n_{\left(v^{2} / g \cdot L\right)}=1 \Rightarrow n_{v}^{2}=n_{L}
$$

which verifies the cinematic similarity condition.

Furthermore, assuming Froude similarity, $(\rho / v)_{\bmod } /(\rho / v)_{\text {prot }}=1$ and being the chosen scale $n_{\mathrm{L}}=n_{\mathrm{mod}} / n_{\text {prot }}=1 / \lambda$, then the 
proportionality between $\mathrm{Re}$ in the model and the prototype is

$$
\text { 14. } \frac{\mathrm{Re}_{\mathrm{m}}}{\mathrm{Re}_{\mathrm{p}}}=\left(\frac{1}{\lambda}\right)^{3 / 2} \Rightarrow \mathrm{Re}_{\mathrm{p}}=\lambda^{3 / 2} \mathrm{Re}_{\mathrm{m}}
$$

Since the scale used was 1:25 (i.e. $\lambda=25$ ), the Re in the model is around 125 times smaller than in the prototype. In fact the model is in $O\left(10^{5}\right)$ while the prototype is in $O\left(10^{7}\right)$. That is, the tests should have used a fluid with kinematic viscosity 125 times smaller in order to keep proportionality in viscous forces with the prototype. So there is a distortion in the value of $C_{\mathrm{d}}$ and it is needed to assess how the proportion in drag forces have been distorted in the estimation of total wave forces.

Furthermore, $C_{\mathrm{d}}$ and $C_{\mathrm{M}}$ show high variability in the vicinity of $\operatorname{Re} \sim 10^{5}$, which is the case of the authors' model. Indeed, a flow passing around a smooth cylinder shows different values of $C_{\mathrm{d}}$ as a function of $\mathrm{Re}$, with a sudden variation in the vicinity of $\operatorname{Re} \sim 10^{5}$, where a turbulent boundary layer separation occurs: the boundary layer partly remains laminar and partly becomes turbulent as well as the wake downstream of the cylinder (sudden transition between subcritical and supercritical zone). This phenomenon was studied by several authors, both from laboratories and in field studies, mostly from the 1950's onwards, with conclusions and results summarised in, amongst others, the Shore Protection Manual (USACE, 1984).

So any approach to the problem should be based on estimations of $C_{\mathrm{d}}^{\text {prot }} / C_{\mathrm{d}}^{\text {mod }}$ and $C C_{\mathrm{M}}^{\text {prot }} / C_{\mathrm{M}}^{\text {mod }}$.

In addition, variations of $C_{\mathrm{M}}$ and $C_{\mathrm{d}}$ with Re are also dependent on the $\mathrm{KC}$, which is the rate between the orbital amplitude of the wave and the diameter of the cylinder

15. $\mathrm{KC}=\frac{A}{D}=\frac{u_{\max } T}{D}$

where $A$ is the orbital amplitude of the wave movement, $D$ is the diameter of the cylinder, $u_{\max }$ is the maximum horizontal wave velocity and $T$ is the wave period.

These curves were described by Sarpkaya (1976) according to the frequency parameter $\beta$.

16. $\beta=\frac{\mathrm{Re}}{\mathrm{KC}}$

In the authors' case, $\mathrm{KC}$ is in the range 15-20 both in the model and the prototype. $C_{M}$ is almost constant $\left(C_{M} \approx 2 \cdot 0\right)$ if $\beta>6000$, as it is in the model; whereas there is high variability as $\beta$ decreases, as occurs at prototype scale. Plus, $\beta$ curves by Sarpkaya (1976) show different shapes and high influence in $C_{d}$ estimation.

Furthermore, if roughness is not modelled properly, the model and the prototype move through different $C_{\mathrm{d}}$ against $\mathrm{Re}$ curves. The relative roughness concept $(K)$, as it was defined by Nikuradse (1933), is defined as follows

17. $K=\frac{k_{\mathrm{s}}}{D}$

where $k_{\mathrm{s}}$ is the equivalent sand diameter. The curves were also described by Sarpkaya (1976).

The influence of $k_{\mathrm{s}} / D$ in $C_{\mathrm{d}}$ can be relevant in this problem, for example, when taking into consideration the effect of marine growth in the cylinders.

Additional issues arise from the fact that the structure itself leads to an increase of wave height in front of the caisson, which also affects $C_{\mathrm{M}}$ and $C_{\mathrm{d}}$ coefficients. Chakrabarti (1994) developed guidance on how $C_{\mathrm{d}}$ should be modified according to $\Phi$ variations due to the blockage effect owing to the presence of several cylinders side by side. In that case, $C_{\mathrm{d}}$ can be called $C_{\mathrm{e}}$ (effective drag coefficient) and changes with Reynolds number also, with different curves depending on whether $R e$ is greater or lower than $4 \cdot 2 \times 10^{5}$.

This blockage effect needs to be assessed when the analysis comes from individual cylinders. However, this effect is already reproduced during physical tests. Anyway $C_{\mathrm{e}}$ variation with $\Phi$ shows different patterns as a function of Re.

To sum up, the key conclusions from the scale effect discussion are as follows.

Assessment of Re number distortion is highly complex for this typology, since it depends on the horizontal wave velocity and acceleration. So it is variable both in time and in depth along the cylinders. In addition, analysis from individual cylinders subjected to steady flows are not completely applicable, since the caisson has a chamber and the maximum wave forces to the caisson do not occur at the same time as the maximum forces in the front cylinders, neither does this necessarily occur with $H_{\max }$ in the case of irregular waves. Thus, tests with regular waves seem to be a good approach for a first estimation of these scale effects.

- The distortion in the Re between the model and the prototype implies a variation in $C_{\mathrm{d}}$. For a single cylinder, the value of the Re number in the prototype is $O\left(10^{7}\right)$ but 
in the model Re is $O\left(10^{5}\right)$, which is located in the transition zone with a high variability of $C_{\mathrm{d}}$.

- For tests with smooth cylinders and small degree of density $\Phi$, the wave loads are inertia dominated and the scale effects are minor.

- However, Re dependency and the roughness of the cylinders compared with that in the field needs to be evaluated with tests for this typology in specific projects. This evaluation is also needed for different values of $\Phi$, since the effective drag coefficient varies differently as a function of Re.

- In addition, it is advisable to test larger ranges of degree of density $\Phi$ (from $\Phi \geq 0 \cdot 50$ ), because the flow velocity (and $\mathrm{Re}$ ) between the front cylinders increases with an increase in $\Phi$.

- According to previous comment, for smooth concrete and $\Phi$ near 0.50 , the increase of forces could be estimated within only $5-10 \%$ in comparison with the direct application of Froude's similarity for loads estimation. However, this factor can be increased significantly for medium and large roughness and high values of $\Phi$, due to the importance of drag forces.

- Finally, the use of Cauchy law scaling of dynamic pressure during the wave impact can lead to a very important underestimation of maximum pressures. Consequently, the use of Cauchy similarity is not recommended for this kind of testing, and Froude similarity, although not perfectly fitted for this type of aeration problems, is preferred to estimate forces in real scale from an engineering viewpoint.

\section{A1.2 Could air entrainment or salty water have a significant impact on the results?}

These kinds of tests are mostly conducted using freshwater and this introduces a laboratory-scale effect due to the fact that air behaves differently in freshwater than in seawater. First of all, an increase of water density of around $2 \cdot 5 \%$ when deriving forces or pressures from the model to the prototype should be taken into account.

However, there are other effects such as the following.

- Air bubbles formed in freshwater tend to be larger than in seawater and they tend to coalesce in the free surface, after rising through the water by buoyancy more easily. Consequently, air can escape more quickly from freshwater than from seawater.

- Higher levels of aeration of seawater produce a greater cushioning effect that reduces the dynamic peak pressures over the structure. It is reasonable to accept that the main difference between freshwater and seawater pressure values is the different levels of aeration within these fluids.
The pressure variation during a wave impact will change the volume of the entrained air and will change the voids ratio.

- Laboratory tests with freshwater and seawater conducted by Bullock et al. (2000) in the University of Plymouth have shown that freshwater peak pressure values were about $10 \%$ higher than those for seawater. However, when rise time was taken into account, the impulse, or the impulsive loading, on the model breakwater was of the same order.

As a conclusion, the authors can state that entrained air might reduce maximum impact pressures and increase rise times. Moreover, freshwater tests considering Froude law lead to a likely overestimation of $10 \%$ in impact pressures. Scale effects do not seem to alter significantly the tests' key conclusions and therefore they can be taken as valid.

\section{REFERENCES}

Akilly H, Akar A, Atakan A et al. (2004) Flow characteristics of circular cylinders arranged side-by-side in Shallow Water. Journal of Flow Measurement and Instrumentation 15(4): 187-197.

Allsop NWH (1995) Vertical walls and breakwaters: optimization to improve vessel safety and wave disturbance by reducing wave reflections. In Wave Forces and Vertical Wall Structures, Task Committee on Forces on Inclined Vertical Wall Structures (Kobayashi N and Demirbilek Z (eds)). American Society of Civil Engineers, New York, NY, USA, pp. 232-258.

Bergmann $\mathrm{H}$ and Oumeraci H (2000) Wave loads on perforated caisson breakwaters. In Coastal Engineering 2000 (Edge BL (ed.)). American Society of Civil Engineers, New York, NY, USA, pp. 1622-1635.

Bullock GN, Hewson P, Crawford AR and Bird PAD (2000) Field and laboratory measurements of wave loads on vertical breakwaters. In Coastal Structures '99 (Losada IJ (ed.)). CRC Press, Boca Raton, FL, USA, pp. 613-621.

Chakrabarti SK (1994) Hydrodynamics of Offshore Structures. Computational Mechanics Publications, WIT Press, Southampton, UK.

Chakrabarti S (2005) Handbook of Offshore Engineering. Elsevier, Amsterdam, the Netherlands, Ocean Engineering series.

EurOtop (2007) EurOtop: Wave Overtopping of Sea Defenses and Related Structures: Assessment Manual (Pullen T, Allsop NWH, Bruce T et al. (eds)). Kuratorium für Forschung im Küsteningenieurwesen, Hamburg, Germany.

Franco C and Franco L (1999) Overtopping formulae for caisson breakwaters with no breaking 3-d waves. Journal of Waterway, Port, Coastal and Ocean Engineering 125(2): 98-107. 
Goda Y (1985) Random Seas and Design of Maritime Structures. University of Tokyo Press, Tokyo, Japan.

Goda Y (2010) Random Seas and Design of Maritime Structures, 3rd edn. World Scientific Publishing, Singapore, Singapore, Advanced Series on Ocean Engineering vol. 33.

Ijima T, Tanaka E and Okuzono H (1976) Permeable seawall with reservoir and the use of 'Warock'. In Coastal Engineering 1976. American Society of Civil Engineers, New York, NY, USA, pp. 2623-2642.

Keulegan GH and Carpenter LH (1958) Forces on cylinders and plates in an oscillating fluid. Journal of Research of the National Bureau of Standards 60(5): 423-440.

Kirca VS and Kabdasli MS (2009) Reduction of non-breaking wave loads on caisson type breakwaters using a modified perforated configuration. Ocean Engineering 36(17-18): 1316-1331.

McConnell KJ, Allsop NWH and Flohr H (1999) Seaward wave loading on vertical coastal structures. In Coastal Structures '99 (Losada IJ (ed.)). Balkema, Rotterdam, the Netherlands, pp. 447-454.

Morison JR, O'Brien MP, Johnson JW and Schaaf SA (1950) The force exerted by surface waves on piles. Petroleum Transactions 189: 149-154.

Nikuradse J (1933) Stromungsgesetz in rauhren rohren. National Advisory Commission for Aeronautics (1950), Washington, DC, USA, Technical Report, NACA Technical Memorandum 1292 (in German).

Ochi MK and Tsai CH (1984) Prediction of impact pressure induced by breaking waves on vertical cylinders in random seas. Applied Ocean Research 6(3): 157-165.

Oumeraci H, Allsop W, de Groot M et al. (1998) Wave Impact Loading and Dynamic Response of Vertically Faced Breakwaters. European Research Project Mast III/PROVERBS, Braunschweig, Germany, Final report, vol. 1.

Paape A (1960) Experimental data on the overtopping of seawalls by waves. In Coastal Engineering: Proceedings of 7th Conference on Coastal Engineering, The Hague, The Netherlands, 1960 (Johnson JW (ed.)). Council on Wave Research, Richmond, CA, USA, vol. 2, pp. 674-681.

Pianc (International Navigation Association) (2003) Breakwaters with Vertical and Inclined Concrete Walls. International Navigation Association, Brussels, Belgium, Maritime Navigation Commission Report WG28.

Puertos del Estado (2005) ROM 0.5-05: Recomendaciones Geotécnicas para Obras Marítimas y Portuarias. Puertos del Estado, Ministerio de Fomento, Gobierno de España, Madrid, Spain (in Spanish).

Sainflou G (1928) Essai sur les digues maritimes verticals. Annales des Ponts et Chaussées 98(4): 5-48 (in French).

Sarpkaya T (1976) Vortex Shedding and Resistance in Harmonic Flow about Smooth and Rough Circular Cylinders at High
Reynolds Numbers. Naval Postgraduate School, Monterey, CA, USA, Report No. NPS-59SL76021.

Sarpkaya T and Isaacson M (1981) Mechanics of Wave Forces on Offshore Structures. Van Nostrand Reinhold, New York, NY, USA.

Sawaragi T and Iwata K (1978) Wave attenuation of a vertical breakwater with two air chambers. Coastal Engineering in Japan, JSCE 21: 63-74.

Takahashi S (2002) Design of Vertical Breakwaters. Marine Environment and Engineering Department, Port and Airport Research Institute, Nagase, Yokosuka, Japan, Revised version 2.1.

Takahashi S, Shimosako K and Sasaki H (1991) Experimental study on wave forces acting on perforated wall caisson breakwaters. Report of the Port and Harbour Research Institute 30(4): 3-34 (in Japanese).

Takahashi S, Tanimoto K and Shimosako K (1994) A proposal of impulsive pressure coefficient for design of composite breakwaters. In Hydro-Port '94 (Port and Harbour Research Institute (ed.)). Coastal Development Institute of Technology, Tokyo, Japan, pp. 489-504.

Tanimoto K and Yoshimoto $Y$ (1982) Theoretical and experimental study of reflection coefficient for wave dissipating caisson with a permeable front wall. Report of the Port and Harbour Research Institute 21(3): 43-78 (in Japanese).

USACE (US Army Corps of Engineers) (1984) Shore Protection Manual, Volume II. Coastal Engineering Research Center, Department of the Army, Waterways Experiment Station, Corps of Engineers, Vicksburg, MS, USA.

Zhu ST and Chwang AT (2001) Investigations on the reflection behaviour of a slotted seawall. Coastal Engineering 43(2): 93-104.

\section{HOW CAN YOU CONTRIBUTE?}

To discuss this paper, please email up to 500 words to the editor at journals@ice.org.uk. Your contribution will be forwarded to the author(s) for a reply and, if considered appropriate by the editorial board, it will be published as discussion in a future issue of the journal.

Proceedings journals rely entirely on contributions from the civil engineering profession (and allied disciplines). Information about how to submit your paper online is available at www.icevirtuallibrary.com/page/authors, where you will also find detailed author guidelines. 